BMJ

Open

Gastroenterology

\section{Adenoma Detection before and after the age of 50: a retrospective analysis of Lebanese outpatients}

To cite: Hussein Kamareddine M, Ghosn Y, Karam K, et al. Adenoma Detection before and after the age of 50: a retrospective analysis of Lebanese outpatients. BMJ Open Gastro 2018;5:e000253. doi:10.1136/ bmjgast-2018-000253

Received 11 October 2018 Revised 26 0ctober 2018 Accepted 29 October 2018
Check for updates

(c) Author(s) (or their employer(s)) 2018. Re-use permitted under CC BY-NC. No commercial re-use. See rights and permissions. Published by BMJ.

${ }^{1}$ Department of Medicine and Medical Sciences, University of Balamand, El-Koura, Lebanon ${ }^{2}$ Department of General Surgery, Saint George Hospital University Medical Center, Beirut, Lebanon

${ }^{3}$ Department of

Gastroenterology, Saint George Hospital University Medical

Center, Beirut, Lebanon

Correspondence to

Dr Said Farhat;

Saidfarhat@hotmail.com

\section{ABSTRACT}

Background and aim Colorectal cancer (CRC) has an increased impact on the Lebanese population's morbidity and mortality. This study evaluated the situation of adenoma detection in an outpatient clinic in Lebanon.

Patients and methods 918 patients underwent colonoscopy over a period of 24 months by a qualified physician. Biopsy results were divided into normal versus abnormal colonic tissue, which was further subdivided into number of polyps and cancer. Results Out of 918 individuals included, 82 cases of Crohn's colitis (8.93\%) and 22 cases of ulcerative colitis $(2.39 \%)$ were identified. A total of 42 cases of CRC $(4.58 \%)$ and 188 cases of adenomatous polyps $(20.48 \%)$ were identified. The data show that age $>50$ years and male gender significantly correlate with increased incidence of precancerous and cancerous polyps. Further exploring the results by age groups and gender, detection of adenomatous polyps in women aged $40-49(8.33 \%)$ was significantly different from their female counterparts aged $\geq 50$ years old $(25.26 \%)$ $(p<0.01)$. However, no statistical difference between detection of adenomas was found between men aged 40-49 (33.33\%) and their male counterparts aged $\geq 50$ years old $(37.5 \%)(p=0.6)$.

Conclusion Within the limitations of this study, the incidence of CRC and adenomatous polyps falls in the high range compared with international studies. Furthermore, symptomatic male patients aged 40-49 appear to exhibit detection rates of adenomas similar to their counterparts aged $\geq 50$ years old. Subjects younger than 50 years underwent diagnostic rather than screening colonoscopy, which introduces some selection bias. Nevertheless, these findings can serve as a basis for further studies.

Colorectal cancer (CRC) is the third most commonly diagnosed type of cancer among men and the second most among women, with men showing significantly higher rates. It is also the second leading cause of death from cancer worldwide. ${ }^{1}$ In Lebanon, CRC is the second most commonly reported cancer in women and the fourth most commonly
Summary box

What is already known about this subject?

- Although screening allows for early diagnosis and removal of precancerous lesions, it is not a common procedure in Lebanon and in low-income and middle-income countries.

- Published data regarding adenoma detection rate, patients $<50$ years old and screening practices are scarce in Lebanon.

What are the new findings?

- The data show that age $>50$ years and male gender significantly correlate with increased incidence of precancerous and cancerous polyps.

- Further exploring the results by age groups and gender, detection of adenomatous polyps in women aged $40-49(8.33 \%)$ was significantly different from their female counterparts aged $\geq 50$ years old $(25.26 \%)$. However, no statistical difference between detection of adenomas was found between men aged 40-49 (33.33\%) and their male counterparts aged $\geq 50$ years old (37.5\%).

How might it impact on clinical practice in the foreseeable future?

- With further studies and comparisons at different institutions, this could represent a modified age of screening for Lebanese men, starting before the age of 50 , directly impacting how we screen our patients in Lebanon.

- This could also serve as a catalyst for more studies on the topic from institutions in the country and in the region (who share similar risk factors), as well as further incentivising physicians in the region on increasing colorectal cancer awareness and screening at appropriate times and intervals.

reported cancer in men as of $2012 .{ }^{2}$

CRC develops in a multistep manner, from the normal epithelium, through a premalignant lesion (adenoma), into a malignant lesion (carcinoma), which invades the surrounding tissues and may eventually spread systemically (metastasis). ${ }^{13}$ The 
adenoma-carcinoma sequence is widely accepted, based on observational studies, as a major pathway for the development and progression of CRC. ${ }^{3}$ Considering the adenoma to carcinoma sequence, removing polyps to prevent CRC is a reasonable course of action. ${ }^{1-3}$

The most effective manner for removing these polyps at an early stage is achieved through screening. Screening allows for early detection and removal of adenomatous polyps, as well as early detection of CRC, creating a more favourable diagnosis as the 5-year survival rate of CRC is approximately $90 \%$ if the disease is localised, $68 \%$ if the disease is regional, and drops to $10 \%$ if distant metastasis ensues. ${ }^{12}$ Screening tools can be divided into two main categories: stool tests and structural exams. ${ }^{1-3}$ Stool tests can be exemplified by tests for occult blood or exfoliated DNA. Flexible sigmoidoscopy, colonoscopy, double-contrast barium enema and CT colonography represent structural exams. ${ }^{13}$ Colonoscopy is the current gold standard for CRC screening as it provides the greatest potential for prevention through polypectomy. ${ }^{1}$ Such a procedure allows for direct mucosal inspection of the entire colon from the appendiceal orifice to the dentate line. ${ }^{12}$ Another advantage of colonoscopy is that it allows for a same-session biopsy by polypectomy. Current guidelines for average-risk women and men recommend colonoscopy at the age of 50 years and every 10 years thereafter because the dwell time transition from adenomatous polyp to CRC is at least 10 years. ${ }^{3}{ }^{4}$ It must be noted that like other procedures, colonoscopy outcomes and performance vary by physician skill, equipment, experience and other factors. This variation created the need for consistent quality measures in colonoscopy. ${ }^{25}$ Quality indicators are measurement tools used to quantify healthcare processes. ${ }^{5}$ Adenoma detection rate (ADR) is the primary colonoscopy quality indicator. It is defined as the proportion of colonoscopies in patients aged $\geq 50$ being screened for the first time in which one or more adenomatous polyps have been detected. ${ }^{5}$ An endoscopist's ADR is inversely correlated with the risk of postcolonoscopy CRC. ${ }^{5}$ In the same light, ADR is dependent on several quality measures, including withdrawal times, caecal intubation rates and quality of bowel preparation. ${ }^{145}$

Recent studies continue to confirm that adenomatous polyps are more common among people aged 50 and above. ${ }^{135}$ However, the discovery of advanced CRC among young patients suggests that several factors should be taken into consideration regarding CRC and adenomatous polyp screening, such as life expectancy, natural history of non-malignant advanced neoplasms, cost and individual risk. ${ }^{6}$ Studies carried out in the USA that have investigated the prevalence of CRC with colonoscopic screening before the age of $50^{67}$ revealed that the prevalence of adenomatous polyps among people in the age range of $40-49$ was $14 \%$. Similarly, the prevalence of adenomatous polyps among people whose age ranges from 50 to 59 was $16 \%$. Thus, prevalence of adenomas between these two groups was quite similar. ${ }^{7}$ Furthermore, several recent studies have shown that male sex, smoking, metabolic syndrome and obesity are risk factors for CRC. ${ }^{8}$ Individuals with such risk factors may benefit from colonoscopic screening before the age of $50 .{ }^{89}$ Furthermore, incidence of adenomatous polyps has been reported to be up to 1.5-fold higher in men than in women, with men aged 40-49 exhibiting adenomatous polyps constituting $40 \%$ of all polyps. This further demonstrates that age and sex are independent factors in adenoma detection. ${ }^{89}$ We currently lack data regarding adenoma prevalence before the age of 50 in our population, prompting our group to undertake this study, which could pave the way for others to conduct prospective studies on asymptomatic Lebanese patients before the age of 50 .

\section{PATIENTS AND METHODS \\ Sampling}

Data to be analysed were gathered in a retrospective fashion from an outpatient clinic located in a Lebanese tertiary hospital centre. In total, 964 patients had undergone colonoscopy with either a random biopsy or a polyp removal biopsy. Colonoscopy was done by a qualified gastroenterologist over a period of 24 months spanning February 2016-February 2018.

\section{Inclusion criteria}

Of the 2680 patients seen, only patients undergoing lower endoscopy were included. Individualised assessment of risk was done on each patient and indications for colonoscopy followed were derived from the current American College of Physicians (ACP) guidelines, as follows: screening for CRC in eligible patients, history of melena or hematochezia, chronic change in bowel habits without explanation or change in bowel habits suggestive of inflammatory bowel disease (IBD), abnormal imaging requiring further investigation, and positive family history of IBD or CRC.

\section{Exclusion criteria}

Patients known to have IBD or CRC undergoing interval colonoscopy were excluded from the study. Colonoscopies done without caecal intubation, an important quality indicator, were also excluded. Exclusion criteria were also applied to any colonoscopy procedure with an Aronchick Scale grade $>2 / 5$. Thus, the total number of patients went down from 964 to 918 (figure 1).

\section{Informed consent}

All participants signed an informed consent to allow for usage of colonoscopic data by virtue of anonymity, whereby their names were translated into binary entities for scientific purposes.

\section{Colonoscopy preparation}

Colonoscopy preparations were evaluated by Aronchick Scale, whereby a score of 1 over 5 is considered adequate and a score of 5 over 5 is inappropriate for evaluation. All 


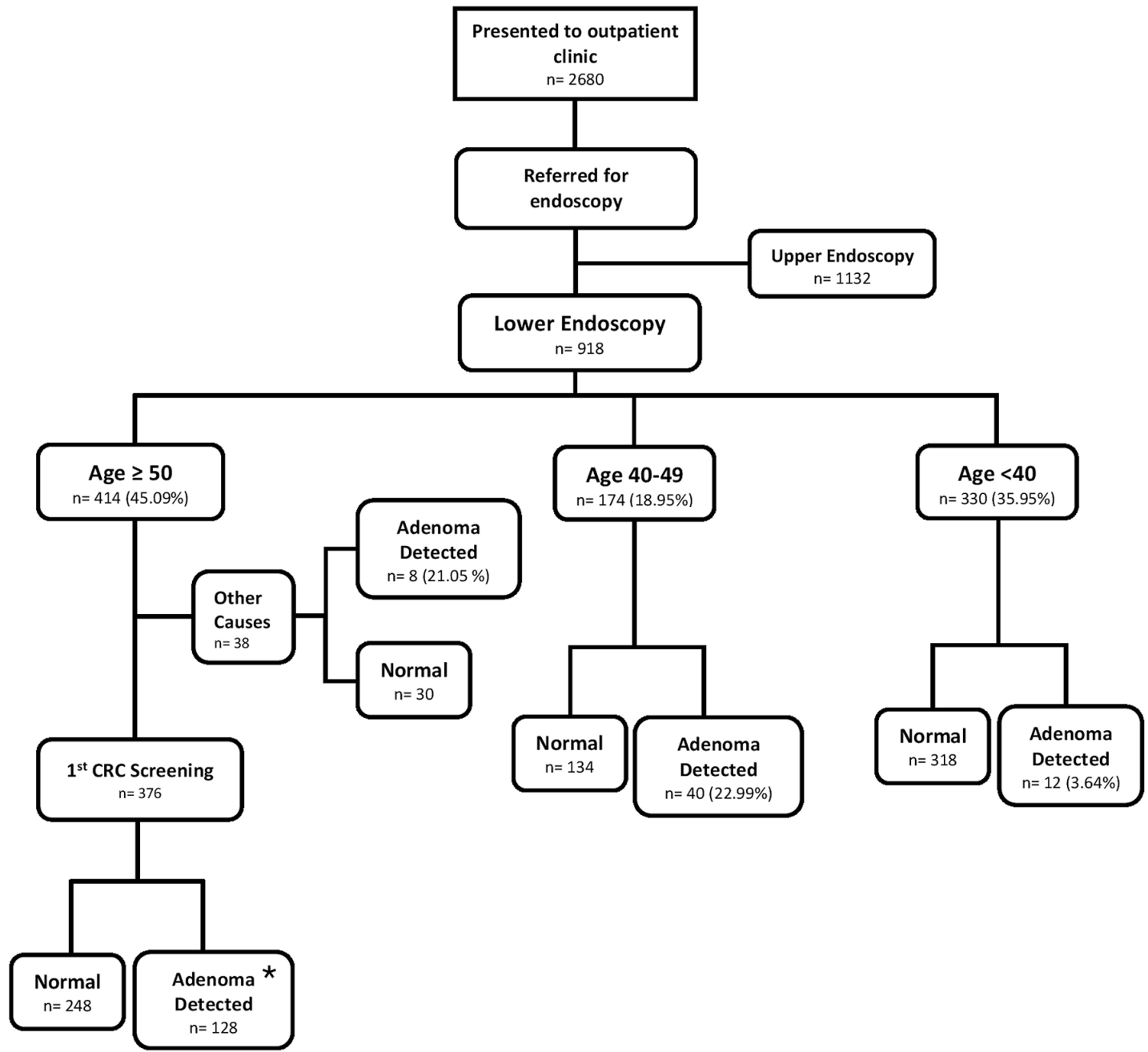

Figure 1 Patients involved in the study and results. *Adenoma detection rate. CRC, colorectal cancer.

patients had complete bowel preparation and cleansing 24 hours prior to colonoscopy.

\section{Colonoscopy procedure}

Colonoscopy took place in a tertiary hospital centre under the care of highly trained staff. Withdrawal times averaged $7.5 \mathrm{~min}$, with the shortest withdrawal time clocking in at $6 \mathrm{~min}$. All patients were consciously sedated and positioned in a lateral decubitus fashion with knees flexed. No complications were reported during both colonoscopy and postcolonoscopy procedures. If no polyps were identified, random biopsies, with a total number of 20, were taken from the colon. This was done in a systematic fashion as follows: rectum, sigmoid, left colon, transverse, right colon and ileocaecal valve. If polyps were identified, polypectomy was done if there were no contraindications, and the samples were sent to pathology laboratory thereafter. If contraindications to polypectomy were present, biopsy was done instead. All biopsies were stored in a $10 \%$ formaldehyde solution and sent to pathology laboratory for further investigation.

\section{Pathology analysis}

Biopsy samples were processed in blocks, whereby microcuts were taken from each biopsied sample and were stained with H\&E. Of note, two qualified pathologists had looked at the slides and had agreed on common results before writing the official report. Results were retrieved based on three variables: age, sex and biopsy results. In the same light, pathology results were divided into two categories: normal versus abnormal colonic tissue. The abnormal section was further subdivided into several categories: number and type of polyps, cancer, and IBD type.

\section{Statistical analysis}

A statistical software package (SPSS V.23.0) was used to analyse the data, whereby independent variables were compared with each other and with dependent variables as well. Descriptive statistics were used to describe patients' characteristics. $\chi^{2}$ analysis was used to determine the differences in detection of adenomas and CRC across age groups. The level of significance was set at $\mathrm{p} \leq 0.05$.

\section{RESULTS AND DISCUSSION}

The total number of patients in our study was 918 after applying the inclusion and exclusion criteria (figure 1). The analysis of the results of these patients selected in the study (figure 2) identified 66 cases of hyperplastic polyps 


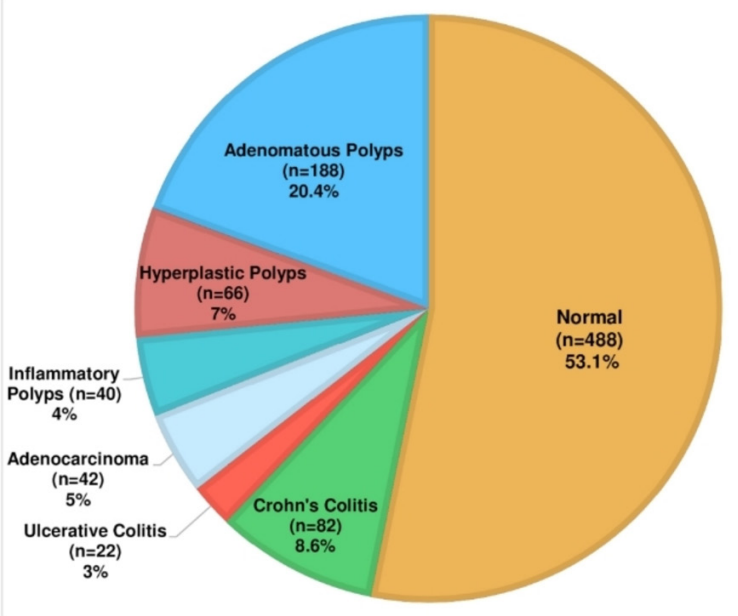

Figure 2 Distribution of colonoscopy results.

and 40 cases of inflammatory polyps. Furthermore, 82 cases of Crohn's colitis were identified, as well as 22 cases of ulcerative colitis, accounting for $8.93 \%$ and $2.39 \%$ of patients seen, respectively. Moreover, 24 patients had abnormal colonic findings that correlated with, but could not be classified as, a form of IBD. A total of 42 cases of adenocarcinoma were identified but no other cancer types were found, leading to an incidence of $4.58 \%$ in our population (table 1 ). Of the 414 patients aged $\geq 50$, 376 had presented for a first-time CRC colonoscopy screening, with adenomas detected in 128 cases leading to an ADR of $34.04 \%$. In total, of the 414 patients who underwent colonoscopy for CRC screening or other diagnostic purposes based on ACP indications, adenomas were detected in 136 cases $(32.85 \%)$.

\begin{tabular}{|c|c|c|}
\hline Variables & $\mathbf{n}$ & $\%$ \\
\hline \multicolumn{3}{|l|}{ Age } \\
\hline$<40$ & 330 & 35.95 \\
\hline $40-49$ & 174 & 18.95 \\
\hline$\geq 50$ & 414 & 45.09 \\
\hline \multicolumn{3}{|l|}{ Sex } \\
\hline Male & 502 & 54.68 \\
\hline Female & 416 & 45.32 \\
\hline \multicolumn{3}{|l|}{ Polyps } \\
\hline No polyps & 730 & 79.52 \\
\hline Polyp(s) & 188 & 20.48 \\
\hline \multicolumn{3}{|l|}{ Number of polyps } \\
\hline $1-2$ & 132 & 70.21 \\
\hline$>2$ & 56 & 29.89 \\
\hline \multicolumn{3}{|l|}{ Cancer } \\
\hline Total cancer cases & 42 & 4.58 \\
\hline Adenocarcinoma & 42 & 4.58 \\
\hline Other & 0 & 0 \\
\hline
\end{tabular}

\begin{tabular}{|c|c|c|c|}
\hline Variables & Age $<50$ & Age $\geq 50$ & $P$ values \\
\hline \multicolumn{4}{|l|}{ Polyp } \\
\hline No polyps & 452 & 278 & $<0.01^{*}$ \\
\hline Polyp(s) & 52 & 136 & \\
\hline \multicolumn{4}{|l|}{ Cancer } \\
\hline No & 500 & 376 & $<0.01^{*}$ \\
\hline Yes & 4 & 38 & \\
\hline
\end{tabular}

*Statistically significant results.

A very small percentage of our population were found to have CRC before the age of 50, without statistical significance $(p>0.1)$. Our population is in accordance with the published data on the development of CRC at age $\geq 50$, displaying $\mathrm{p}<0.01$ (table 2).

Age, and its correlation to CRC and other colonic diseases, has been studied at length with numerous meta-analyses, displaying a significant rise in the rate of CRC after the age of $50 .{ }^{10}$ Our data show that age $>50$ years significantly correlates with an increased incidence of precancerous polyps in the colon, with $\mathrm{p}<0.01$ (table 2). Polyps are more frequent in male sex with a significant correlation: $\mathrm{p}<0.01$ (table 3 ). Once the data are stratified into age ranges (table 4), the findings are more intriguing. There was no statistically significant difference in detection of adenomas between patients aged $\geq 50(32.85 \%)$ and those aged $40-49(22.99 \%)$. However, once further stratified by sex, we note age $\geq 50$ significantly correlates with an increased detection of adenomas in women $(25.26 \%)(\mathrm{p}<0.01)$ compared with the age range of $40-49(8.33 \%)$. On the other hand, there was no statistically significant difference in detection of adenomas between men aged $\geq 50(37.5 \%)$ and men aged $40-49(33.33 \%)$, with a $\mathrm{p}=0.53$. A similar incidence of polyps in men aged 40-49 and their $\geq 50$ counterparts is not in accordance with existing data.

Studies have shown that sex also plays an important role in the development of CRC, with men found to be at an increased risk for developing CRC compared with their female counterparts. A previous meta-analysis

Table 3 Comparison of polyp and cancer detection by gender

\begin{tabular}{llcl}
\hline & \multicolumn{2}{l}{ Sex } & \\
\cline { 2 - 3 } Variables & Male & Female & P values \\
\hline Polyp & & & \\
No polyps & $383(41.72 \%)$ & $357(38.88 \%)$ & $<0.01^{*}$ \\
Polyp(s) & $119(12.96 \%)$ & $59(6.42 \%)$ & \\
Cancer & & & \\
No & $474(51.6 \%)$ & $402(43.79 \%)$ & 0.343316 \\
Yes & $28(3.05 \%)$ & $14(1.53 \%)$ & \\
\hline
\end{tabular}

*Statistically significant results. 
Table 4 Comparison of adenoma detection in patients aged $40-49$ and those aged $\geq 50$

\begin{tabular}{|c|c|c|c|}
\hline & Normal & $\begin{array}{l}\text { Adenoma } \\
\text { (detection rate of } \\
\text { adenoma, \%) }\end{array}$ & $P$ values \\
\hline Patients aged $<50$ & 452 & $52(10.32)$ & $<0.01^{\star}$ \\
\hline Patients aged $\geq 50$ & 278 & $136(32.85)$ & \\
\hline $\begin{array}{l}\text { Patients aged } \\
40-49\end{array}$ & 134 & 40 (22.99) & $<0.01^{\star}$ \\
\hline Patients aged $\geq 50$ & 278 & 136 (32.85) & \\
\hline $\begin{array}{l}\text { Women aged } \\
40-49\end{array}$ & 66 & $6(8.33)$ & $<0.01^{\star}$ \\
\hline Women aged $\geq 50$ & 142 & $48(25.26)$ & \\
\hline Men aged $40-49$ & 68 & 34 (33.33) & 0.6 \\
\hline Men aged $\geq 50$ & 140 & 84 (37.5) & \\
\hline
\end{tabular}

${ }^{*}$ Statistically significant results.

demonstrated a relative risk of 1.83 (95\% CI 1.69 to 1.97$)$ for CRC in men compared with women. ${ }^{11}$

Our results are in accordance with these data, with the male sex shown to be significantly associated with polyps $(\mathrm{p} \leq 0.01)$ (table 3$)$. As polyploidy predisposes to CRC via the adenoma-carcinoma sequence, correlations can be made between sex and future development of CRC. These data and the aforementioned increase in polyploidy in our male population after the age of 40 highlight the need for a systematic approach for colonoscopy and CRC screening in the male sex possibly even before the age of 50.

Extensive research has been carried out on the effect of environmental factors such as alcohol, type of diet and smoking on the risk of CRC. ${ }^{12}$ In terms of alcohol consumption, a study by Fedirko et $a l^{13}$ found a $7 \%$ increase in CRC per daily unit of alcohol consumed. Furthermore, diets rich in red meat have been directly linked to an increased CRC risk, while those rich in fruit and fibre content have been inversely related to CRC incidence. Another meta-analysis of 116 studies showed a relative risk of 1.12 (95\% CI 1.09 to 1.16$)$ of CRC in those with high red meat intake versus those with low red meat intake. ${ }^{12}$ In contrast to very little fruit and fibre consumption, the relative risk of CRC was 0.91 (95\% CI 0.85 to 0.96 ) for one serving per day and decreased with increased servings per day. Although a Mediterranean country, Lebanon's current diet with its high portions of red meat is a far cry from the recommended Mediterranean diet found to be preventative of CRC, further signified by the fact that only $3.6 \%$ of our studied population follows a vegetarian diet. ${ }^{14}$ Regarding body mass index (BMI), the association between it and CRC is significant, with a relative risk of 1.10 per $\mathrm{kg} / \mathrm{m}^{2}$ (95\% CI 1.08 to 1.12). ${ }^{12}$ Moreover, this association between BMI and CRC was stronger for men than it was for women, with relative rates being 1.29 per $\mathrm{kg} / \mathrm{m}^{2}$ and 1.15 per $8 \mathrm{~kg}$ / $\mathrm{m}^{2}$, respectively. Furthermore, a recent study has shown that $52.77 \%$ of the Lebanese population is overweight or obese, $70 \%$ of men and $34 \%$ of women. ${ }^{15}$ In another meta-analysis conducted by Botteri et al, ${ }^{16}$ smoking was linked with an absolute risk increase of 10.8 cases of CRC per 100000 person-years (95\% CI 7.9 to 13.6). A recent study on smoking in Lebanon ${ }^{17}$ demonstrated an overall prevalence rate of $34.7 \%$, which is high when compared with international and even regional estimations. Moreover, significantly higher rates of smoking were observed in men than in women $(42.9 \%$ and $27.5 \%$, respectively). With all these factors in mind, we conclude that the Lebanese population, especially men, is in the high-risk range for developing CRC. Increasing awareness of these risk factors and developing efficient surveillance for the affected population are of high importance as colonoscopy allows for the diagnosis of, and in some instances treatment of, these colonic abnormalities at an early stage, creating a favourable prognosis.

Although most CRC cases are due to sporadic mutations via the adenoma-carcinoma sequence, hereditary and genetic factors are implicated in approximately $35 \%$ of CRC cases. From the mutated APC gene in familial adenomatous polyposis, to mismatch repair gene seen in hereditary non-polyposis colorectal cancer, and the more than 40 genetic loci identified by genome-wide association studies, these mutations confer increasing risk of CRC. ${ }^{18}$ Although definite percentages are not documented, a conclusion of high prevalence of interfamilial marriage in Lebanon can be easily appreciated with basic demographic visualisations. This may manifest as an increase in the incidence and earlier appearance of CRC.

Finally, with recent estimates of incidence of CRC in Lebanon being $54.1 / 100000,{ }^{19}$ the Lebanese population appears to be at a higher risk of developing CRC compared with the rest of the world. Our data on polyploidy appear to be in accordance with that observed globally, with the exception of men aged 40-49 which demonstrated no significant difference in polyploidy compared with those aged $\geq 50$. It should be noted, however, that those having undergone colonoscopy before the age of 50 in our population were symptomatic with complaints of hematochezia, unexplained and refractory abdominal pain, alterations in bowel movements, and so on. Therefore, our data should be used as a pillar for future studies where ADR can be specified in asymptomatic patients across different age groups, such as those carried out in other countries. ${ }^{9}$ A national survey as well as a national database would be an excellent first step towards further understanding the risk of CRC in the Lebanese population, which appears to be similar to that observed in Europe and North America. ${ }^{19}$

\section{CONCLUSION}

With the limitations of this study, we find that colonic diseases display a high incidence in the Lebanese population. Our study, which was conducted in an outpatient clinic, shows high-range prevalence of polyploidy 
compared with similar European and American studies. Also of note is the prevalence of polyploidy in men aged $40-49$, which did not statistically differ from that in men aged $\geq 50$. Our data are biased because of the outpatient setting and since colonoscopy in those aged $<50$ was conducted only on symptomatic patients, but could be used as a basis for further investigations. In light of a reported $3.2 \%$ annual increase of incidence rates of CRC among adults aged $<50$ since the mid-1990s, ${ }^{20}$ the authors wonder if screening initiation in Lebanese men $<50$, specifically those aged $40-49$, should be considered. Further studies and data regarding polyposis in asymptomatic patients aged 40-49 are needed in order to inform decisions to create sex-specific recommendations for CRC screening in our population.

Contributors MHK, ME-K and SF conceived of the presented idea. MHK, NB-A, YG, KK and AAN wrote the manuscript. KK, NB-A, AAN and AE-M entered the data. MHK, SF and YG developed the theory and performed the statistical analysis. MHK, $M E-K$ and $Y G$ created the tables and figures for the manuscript. SF supervised the project.

Funding The authors have not declared a specific grant for this research from any funding agency in the public, commercial or not-for-profit sectors.

Competing interests None declared.

Patient consent Obtained.

Provenance and peer review Not commissioned; externally peer reviewed.

Data sharing statement № additional unpublished data are available.

Open access This is an open access article distributed in accordance with the Creative Commons Attribution Non Commercial (CC BY-NC 4.0) license, which permits others to distribute, remix, adapt, build upon this work non-commercially, and license their derivative works on different terms, provided the original work is properly cited, appropriate credit is given, any changes made indicated, and the use is non-commercial. See: http://creativecommons.org/licenses/by-nc/4.0

\section{REFERENCES}

1. Global Burden of Disease Cancer Collaboration, Fitzmaurice $C$, Allen $\mathrm{C}$, et al. Global, regional, and national cancer incidence, mortality, years of life lost, years lived with disability, and disability-adjusted life-years for 32 cancer groups, 1990 to 2015: a systematic analysis for the global burden of disease study. JAMA Oncol 2017;3:524-48.
2. Shamseddine Al, Musallam KM. Cancer epidemiology in Lebanon. Middle East Journal of Cancer 2010;1:41-4.

3. Carvalho B, Sillars-Hardebol AH, Postma C, et al. Colorectal adenoma to carcinoma progression is accompanied by changes in gene expression associated with ageing, chromosomal instability, and fatty acid metabolism. Cell Oncol 2012;35:53-63.

4. Winawer S, Fletcher R, Rex D, et al. Colorectal cancer screening and surveillance: clinical guidelines and rationale-Update based on new evidence. Gastroenterology 2003;124:544-60.

5. Anderson JC, Butterly LF. Colonoscopy: quality indicators. Clin Trans/ Gastroenterol 2015;6:e77.

6. Imperiale TF, Wagner DR, Lin CY, et al. Results of screening colonoscopy among persons 40 to 49 years of age. N Engl J Med 2002;346:1781-5.

7. Rundle AG, Lebwohl B, Vogel R, et al. Colonoscopic screening in average-risk individuals ages 40 to 49 vs 50 to 59 years. Gastroenterology 2008:134:1311-5.

8. Jung YS. Is colorectal cancer screening necessary before 50 years of age? Intest Res 2017;15:550-1.

9. Bae T, Ha Y, Kim C, et al. Distribution of the colonoscopic adenoma detection rate according to age: is recommending colonoscopy screening for koreans over the age of 50 safe? Ann Coloproctol 2015;31:46-51.

10. Thrumurthy SG, Thrumurthy SS, Gilbert CE, et al. Colorectal adenocarcinoma: risks, prevention and diagnosis. $B M J$ 2016;354:i3590.

11. Nguyen SP, Bent $\mathrm{S}$, Chen $\mathrm{YH}$, et al. Gender as a risk factor for advanced neoplasia and colorectal cancer: a systematic review and meta-analysis. Clin Gastroenterol Hepatol 2009;7:676-81.

12. Johnson CM, Wei C, Ensor JE, et al. Meta-analyses of colorectal cancer risk factors. Cancer Causes Control 2013;24:1207-22.

13. Fedirko V, Tramacere I, Bagnardi V, et al. Alcohol drinking and colorectal cancer risk: an overall and dose-response meta-analysis of published studies. Ann Oncol 2011;22:1958-72.

14. Donovan MG, Selmin OI, Doetschman TC, et al. Mediterranean diet: prevention of colorectal cancer. Front Nutr 2017;4:59.

15. Mallat S, Geagea AG, Jurjus RA. Obesity in lebanon: a national prsity in Lebanon: a national problem. World J Cardiovasc Dis 2016;06:166-74.

16. Botteri $\mathrm{E}$, lodice $\mathrm{S}$, Bagnardi $\mathrm{V}$, et al. Smoking and colorectal cancer: a meta-analysis. JAMA 2008;300:2765-78.

17. Sibai AM, Iskandarani $M$, Darzi $A$, et al. Cigarette smoking in a Middle Eastern country and its association with hospitalisation use: a nationwide cross-sectional study. BMJ Open 2016;6:e009881.

18. Song N, Shin A, Park JW, et al. Common risk variants for colorectal cancer: an evaluation of associations with age at cancer onset. Sci Rep 2017;7:40644.

19. Saber T, Bedran K, Ghandour F, et al. Results from a retrospective analysis of colonoscopies for Inflammatory bowel disease and colorectal cancer in a Lebanese tertiary care centre. BMJ Open Gastroenterol 2017;4:e000167.

20. Siegel RL, Fedewa SA, Anderson WF, et al. Colorectal cancer incidence patterns in the United States, 1974-2013. JNCl: Journal of the National Cancer Institute 2017;109. 